\title{
La oftalmología y su relevancia en enfermedades sistémicas
}

\section{Ophthalmology and its importance in systemic diseases}

\author{
Matilde Ruiz Cruz*
}

Citar como: Ruiz CM. La oftalmología y su relevancia en enfermedades sistémicas. An Med (Mex). $2020 ; 65$ (4): 254.

https://dx.doi.org/10.35366/97461

Actualmente la oftalmología ha tenido importantes avances tecnológicos, tanto en diagnóstico como en tratamiento, dentro de sus diferentes subespecialidades: retina, uveítis, glaucoma, estrabismo, córnea, oculoplástica, neuroftalmología, segmento anterior, oftalmopediatría, por mencionar algunas. Por ello es de suma importancia dar a conocer lo que está sucediendo en nuestro país. Cabe mencionar que la revisión del segmento anterior y fondo de ojo puede aportar información valiosa en enfermedades sistémicas autoinmunes o infecciosas, siendo muchas de las veces lo que orienta al diagnóstico. Como ejemplo, tenemos a aquellos pacientes con panuveítis por sífilis ocular como única manifestación de inmunosupresión adquirida que no ha sido diagnosticada, o la presencia de escleritis con necrosis como signo inicial en pacientes que padecen granulomatosis con poliangeítis.

El presente número está dedicado a nuestra especialidad. Como editora invitada ha sido un gran honor trabajar en la elaboración del mismo, en con- junto con médicos especialistas egresados de tres grandes instituciones formadoras de oftalmólogos en nuestro país: el Instituto de Oftalmología Conde de Valenciana, la Asociación para Evitar la Ceguera en México y el Hospital de Nuestra Señora de la Luz.

El Centro Médico ABC y el Instituto de Oftalmología Conde de Valenciana han sabido trabajar de manera conjunta y coordinada formando una práctica médica grupal de oftalmología, reuniendo a médicos de las tres instituciones previamente mencionadas, quienes, además, han contado con el apoyo de médicos de otras especialidades pertenecientes al Centro Médico ABC (reumatólogos, infectólogos, médicos internistas, entre otros) tanto a nivel médico como quirúrgico, lo que ha favorecido el manejo multidisciplinario de los pacientes y el trabajo en equipo con altos estándares de calidad.

Éste es el primer número de la Revista Anales Médicos en el que participa oftalmología como práctica médica grupal, y esperamos poder seguir colaborando en futuras publicaciones.

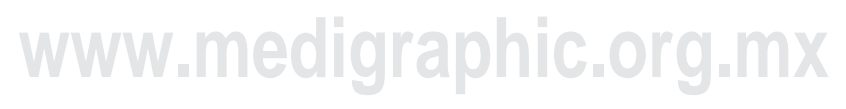

* Oftalmología. Subespecialidades en: Cirugía de Vítreo y Retina; Enfermedades Inflamatorias Oculares y Uveítis. Maestría en Ciencias Médicas. Instituto Nacional de Ciencias Médicas y Nutrición Salvador Zubirán. UNAM. Ciudad México, México.

Recibido para publicación: 06/11/2020. Aceptado: 17/11/2020.

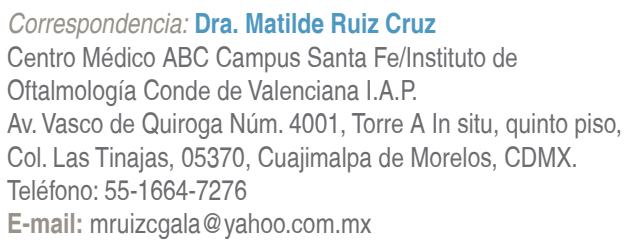

